\title{
Die Uufgaben Der

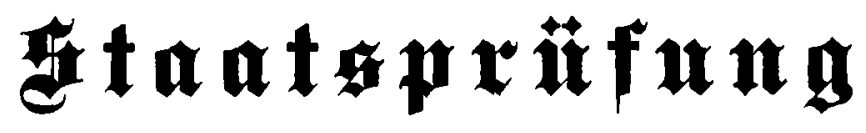 für den
}

höheren Juftiz: und Derwaltungsoientt

in $\mathfrak{b a n e r n .}$

1919

Geft 2: prüfung Gerbft 1919.

Mit amtlicher Erlaubnis.

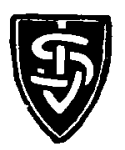

unindien 1919.

3. Sabeizer Derlag (Zurthur Sellier). 


\section{unentbehrlidje Qiteratur

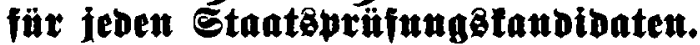

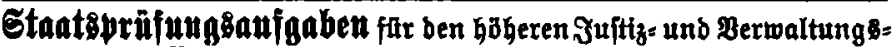
bienit in Babern.

Jahrgang 1919 peft 1 (ßrtffung Frritjahr 1919).

Jahrgang 1918 . Dlt. 1.- (bagu $25 \%$ Berlag s=xeuerungazuldiag). Э̧ahrg. 1906-1913, 1916, 1917 und 1918, 10 3ahrg.

zufammengenommen. Eruāâtgter \$reiz̨ ? Mt. 6.-

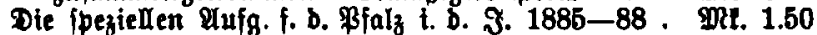
Dte Jalurgănge 1880-84, 1896-98, 1900 unb 1905 find bergriffen.

Die घbrigen Jahrgănge 1885-1900 tojten einjeln à 9Rt. -.50; $1901-1913$ und 1916 à pit. 1.-.

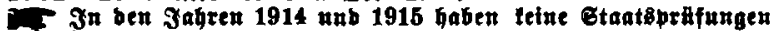
ftattgefurben.

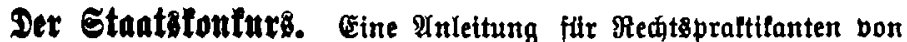
Theobor von ber Bforbten, Oberregterungsirat im Bayer. Jujtiz=

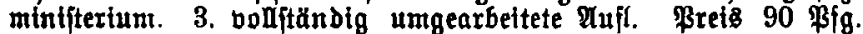
(bazu $25 \%$ Berlagb=TeuerungszufdIag).

Der bienfilide Bertebr and die Gutgiprade auf ber Grund= lage ber Belanntmađung ber Bibil=Staatsminifterten b. 28. April

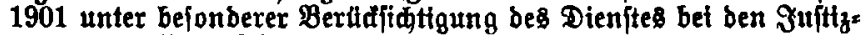
behöben. Bon Theobor von ber Bforbten, Dberregterungsrat im Bayer. Suftizminifterium. Plt Den Minifterialbelant= madungen vom 8. Upril, 5. Sunt und 7. September 1911 be=

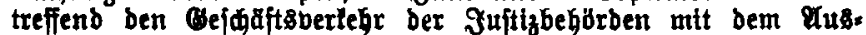
lanbe, exlăutert unb mit frormularmuftern berfehen bon 3. B l eyer, II. Staatsanmalt im bayer. Jujtizmintitertum, $8^{\circ}$.

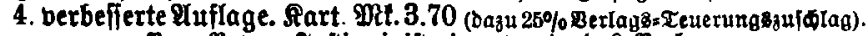
Bom gaver. Juftizutinifterium wurbe bas $9 u$ filis alle Beridt sbehörben Banerns angeidaffit.

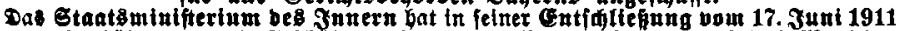

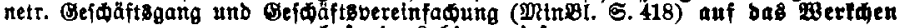
befonber hingewiefert.

Die Borbebiugungen für Den bäberen Juftiz=, Berwaltungs: unb Finaugbienft in Maberu. Eine Sammlung ber $\mathfrak{B o r}$ -

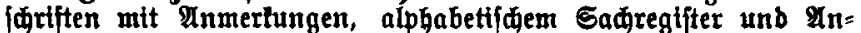
hang. Bon E. Codert, I. Staatsantwalt im Staatsminiftertum

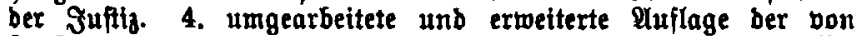

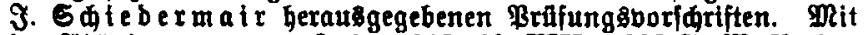

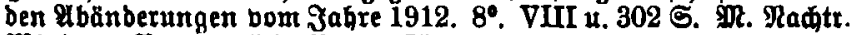

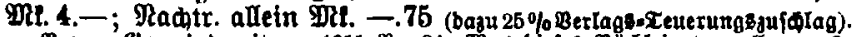

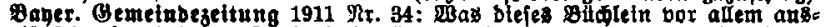

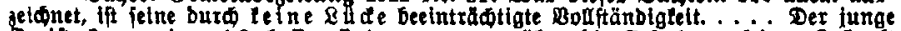
Gurlft Paun nirgenbs befier finben, toos er Hber bie Beftalturg jeiner Bulunft

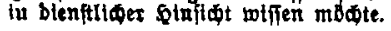

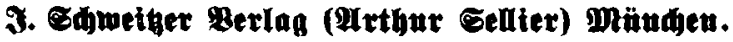


Die

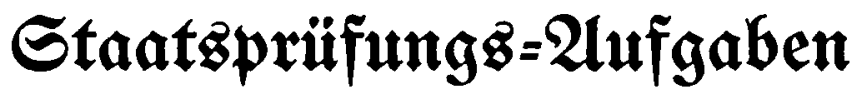

\author{
$\mathfrak{i m} \mathfrak{I a b r e}$
}

1919. 
Drut von Dr. ₹. \$. Datterer \& Eie., Freifing. 